\title{
The burden of minimal hepatic encephalopathy: from diagnosis to therapeutic strategies
}

\author{
Lorenzo Ridola ${ }^{a}$, Vincenzo Cardinale ${ }^{a}$, Oliviero Riggio ${ }^{b}$
}

Sapienza University of Rome, Italy

\section{Abstract}

\section{Introduction}

\section{Definition and epidemiology}

Hepatic encephalopathy (HE) is a complex neurological syndrome, typical of liver cirrhosis, which produces a wide and complex spectrum of nonspecific neurological and psychiatric manifestations [1]. In its mild expression, i.e., minimal HE (MHE) [2,3], this condition alters the performance of psychometric tests, working memory, psychomotor speed, and visuospatial ability, as well as electrophysiological and other functional brain measures, without, however, any evidence of clinical manifestations $[4,5]$. MHE is a frequent complication of liver disease and is considered as one of its most debilitating

Departments of ${ }^{\mathrm{M} M e d i c o-S u r g i c a l ~ S c i e n c e s ~ a n d ~ B i o t e c h n o l o g i e s ~}$ (Lorenzo Ridola, Vincenzo Cardinale); ${ }^{\mathrm{b} C l i n i c a l}$ Medicine (Oliviero Riggio), Sapienza University of Rome, Italy

Conflict of Interest: None

Correspondence to: Lorenzo Ridola, Department of Medico-Surgical Sciences and Biotechnologies, Sapienza University of Rome, Corso della Repubblica, 04110 Italy, e-mail: lorenzo.ridola@uniroma1.it

Received 26 June 2017; accepted 29 November 2017; published online 1 February 2018

DOI: https://doi.org/10.20524/aog.2018.0232 manifestations, severely affecting the life of patients and caregivers. Furthermore, cognitive impairment associated with cirrhosis results in the use of more healthcare resources in adults in comparison with other manifestations of liver disease [6-11].

Depending on the population studied and the diagnostic tool used, MHE occurs in 20-80\% of patients with cirrhosis [12-17], MHE is considered as a preclinical stage of HE and is part of a wide spectrum of typical neurocognitive alterations in liver cirrhosis, particularly involving the areas of attention, alertness, response inhibition, and executive functions [18-21]. Although these typical characteristics of MHE reduce the safety and quality of life (QoL) of patients with cirrhosis, together with their caregivers, they are difficult to detect from the clinical point of view. Moreover, cirrhotic patients with sleep disorders [22-25] also show deficits in executive functions and in specific activities such as driving, which are dangerous for themselves and for others. As low-grade HE is difficult to diagnose (grade I), a recent classification, introducing the term "covert", has been established that combines MHE and Grade I HE. The aim is to simplify the clinical pattern thereby easily and uniformly diagnosing the presence of clinically overt HE (OHE), as reported in Fig. 1 [26]. The term "covert" has been debated since the condition is not really unapparent (latent, subclinical, minimal), but is simply not overt, obvious and severe or clinically unquestionable. The operative characteristics of MHE and covert $\mathrm{HE}$ (CHE) are reported in Table 1 . 
Table 1 Operative characteristics of minimal and covert hepatic encephalopathy

\begin{tabular}{ll}
\hline Minimal hepatic encephalopathy $\quad$ Covert & $\begin{array}{l}\text { - Psychometric or neuropsychological alterations of tests exploring psychomotor speed/ } \\
\text { executive functions or neurophysiological alterations without clinical evidence of mental } \\
\text { change }\end{array}$ \\
Grade I & - Trivial lack of awareness \\
& - Euphoria or anxiety \\
& - Shortened attention span \\
- Impairment of addition or subtraction & - Altered sleep rhythm \\
\hline
\end{tabular}

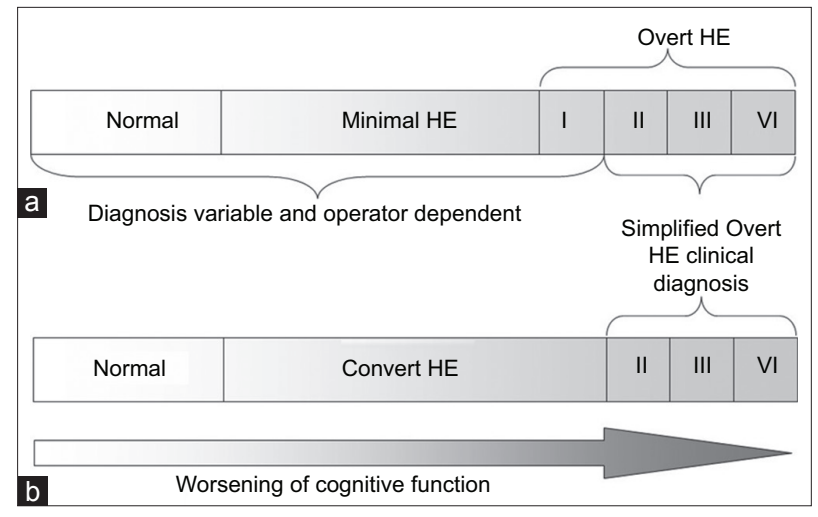

Figure 1 Box A: Classic classification of minimal and overt hepatic encephalopathy (HE). Box B: New classification combining minimal $\mathrm{HE}$ and Grade I HE, in order to simplify the clinical pattern and easily and uniformly diagnose the presence of clinical overt $\mathrm{HE}$

MHE and CHE are risk factors for the development of OHE. In fact, the risk for the first bout of OHE is 5-25\% within 5 years after cirrhosis diagnosis, depending on risk factors, such as other complications related to cirrhosis (MHE or CHE, infections, variceal bleeding, or ascites) and possibly diabetes and hepatitis C [27-31].

\section{The burden of MHE}

Up to $80 \%[1,4,16,32]$ of patients with liver cirrhosis show neuropsychological and neurophysiological abnormalities that are not detectable by the clinical evaluation usually used to identify the presence of HE; these include cognitive and attention deficits, loss of inhibitory response, loss of working memory, and lack of visuomotor coordination. MHE is detected in clinically asymptomatic patients using appropriate psychometric tests and neurophysiological methods (Table 2) that highlight neuropsychological alterations, such as videospatial orientation deficits, attention disorders, memory, reaction time, electroencephalogram (EEG) slowing, prolongation of latency-evoked cognitive potentials and reduction in the critical flicker frequency (CFF).

The optimal diagnostic criteria for MHE remain controversial, also because an essential condition for MHE diagnosis is the correct standardization of the tests used by age, education and also employment of the patient. To overcome the difficulties in the execution of complex psychometric batteries, which may require specialist staff for their administration, are time and money consuming, other techniques have been proposed, such as the CFF, the smooth pursuit eye movement, and the use of cognitive evoked potentials. Computerized psychometric tests, including the scan test [32] and the inhibitory control test (ICT) [33], which may be more specific and repeatable, have also been proposed. An EEG [34] is also useful for detecting MHE conditions, especially if a spectral analysis is carried out [7]. A comprehensive discussion of these diagnostic techniques is given below.

A survey of the American Association for the Study of Liver Diseases, conducted in 2007 [35], showed that most clinicians believe MHE to be a significant problem. However, only 50\% of clinicians had investigated whether their patients might have MHE, and 38\% had never studied their patients with liver cirrhosis using psychometric assessment. MHE reduces patients' QoL, increases the incidence of disability, and has a negative effect on their daily activities. The impact of the perception of the disease, in the form of a "Sickness Impact Profile", has been studied in a group of patients with cirrhosis to assess the indicators of QoL, such as sleep, rest, eating, work, home management, recreation, walking, daily care, movement and emotional behavior. Each profile was significantly reduced in patients with MHE compared to individuals without MHE [36]. In addition, in the presence of MHE, QoL indicators, such as the ability to drive a car, and the incidence of sleep disorders were also negatively affected [37].

\section{MHE and QoL}

Although cirrhosis has a poor prognosis, recent advances in the treatment strategies and general management of this disease have significantly improved survival rates. The majority of patients eligible for liver transplantation now survive until the transplant for between 1 and 4 years. In addition to the stabilization of the disease, it is thus essential for the economic impact, as well as the human and emotional burden of liver cirrhosis, to be taken into account in the management of these patients.

Several studies have shown that liver diseases severely worsen the health-related QoL (HRQoL) [38-40], especially in relation to hospitalizations, severity of the disease, and its complications such as recurrent HE or OHE. Recent evidence suggests that OHE leads to persistent cognitive impairment even after its resolution. In fact, those patients with a prior episode of OHE, although clinically free, may show an increase in the prevalence of cognitive impairment, which can 
be identified by testing for the presence of MHE or learning ability $[41,42]$.

In accordance with the growing interest in the central role of perception in a patient's state of health, the evaluation of HRQoL is acquiring great importance in clinical practice as well as in planning therapeutic strategies. It has in fact already been shown that "quality" and "disability" have a stronger impact than "longevity" on patients' expectation of life [43]. Although HRQoL may appear to be influenced by the presence of MHE [10,36,37,44,45], this evidence is controversial and little is known about the effects of a previous history of HE on HRQoL. Moreover, in patients with a history of

Table $2^{\star}$ Testing strategies for minimal hepatic encephalopathy

\begin{tabular}{|c|c|c|c|c|c|}
\hline Test & Tested domain & Copyright & $\begin{array}{l}\text { Dedicated } \\
\text { (Europe-Asia/USA) }\end{array}$ & $\begin{array}{l}\text { Time required for } \\
\text { administration and } \\
\text { interpretation }(\mathrm{min})\end{array}$ & Comments \\
\hline NCT-A & Psychomotor speed & Yes & $\mathrm{No} / \mathrm{No}$ & $1-2$ & Poor specificity \\
\hline$N C T-B$ & $\begin{array}{l}\text { Psychomotor speed, set } \\
\text { shifting, divided attention }\end{array}$ & Yes & $\mathrm{No} / \mathrm{No}$ & $1-3$ & Poor specificity \\
\hline$B D T$ & $\begin{array}{l}\text { Visuospatial reasoning, } \\
\text { praxis, psychomotor speed }\end{array}$ & Yes & No/Yes & $10-20$ & $\begin{array}{l}\text { It can be used for dementia } \\
\text { testing as well }\end{array}$ \\
\hline DST & Psychomotor speed, attention & Yes & No/Yes & 4 & $\begin{array}{l}\text { Tends to be very sensitive and is } \\
\text { an early indicator }\end{array}$ \\
\hline$L T T$ & $\begin{array}{l}\text { Psychomotor speed, } \\
\text { visuomotor ability }\end{array}$ & Yes & No/Yes & $2-4$ & $\begin{array}{l}\text { Outcomes are errors and time; } \\
\text { tests a balance between speed } \\
\text { and accuracy }\end{array}$ \\
\hline$S D T$ & Psychomotor speed & Yes & No/Yes & $1-2$ & $\begin{array}{l}\text { Only tests psychomotor speed } \\
\text { but has a higher sensitivity than } \\
\text { DST }\end{array}$ \\
\hline PHES & $\begin{array}{l}\text { Psychomotor speed, set } \\
\text { shifting, attention, visual } \\
\text { perception and visuospatial } \\
\text { orientation, visuomotor } \\
\text { ability }\end{array}$ & Yes & No/Not for all tests & 15 & \\
\hline R-BANS & $\begin{array}{l}\text { Verbal/visual/working } \\
\text { memory, visuospatial, } \\
\text { language, and psychomotor } \\
\text { speed }\end{array}$ & Yes & No/Yes & 35 & $\begin{array}{l}\text { Has been primarily studied } \\
\text { in dementia and brain injury. } \\
\text { Limited HE experience }\end{array}$ \\
\hline $\begin{array}{l}\text { Animal- naming } \\
\text { test }\end{array}$ & $\begin{array}{l}\text { Semantic fluency test, verbal } \\
\text { retrieval and recall }\end{array}$ & No & No & 1 & $\begin{array}{l}\text { Easy tool for caregivers } \\
\text { for identify mental status } \\
\text { alterations, for illiterate patients, }\end{array}$ \\
\hline ICT & $\begin{array}{l}\text { Response inhibition, working } \\
\text { memory, vigilance, attention }\end{array}$ & Yes & No/No & $15-20$ & $\begin{array}{l}\text { Need highly functional patients, } \\
\text { familiarity with computers may } \\
\text { be needed }\end{array}$ \\
\hline SCAN test & $\begin{array}{l}\text { Working memory, vigilance, } \\
\text { attention }\end{array}$ & Yes & No/No & $15-20$ & \\
\hline$E E G$ & Generalized brain activity & No & Yes/Yes & $10-15$ & $\begin{array}{l}\text { Can be performed in } \\
\text { comatose patients }\end{array}$ \\
\hline $\begin{array}{l}\text { Visual evoked } \\
\text { potentials }\end{array}$ & $\begin{array}{l}\text { Interval between visual } \\
\text { stimulus and activity }\end{array}$ & No & Yes/Yes & May vary & $\begin{array}{l}\text { Highly variable and poor overall } \\
\text { results }\end{array}$ \\
\hline $\begin{array}{l}\text { Brainstem } \\
\text { auditory evoked } \\
\text { potentials }\end{array}$ & $\begin{array}{l}\text { Response in the cortex after } \\
\text { auditory click stimuli }\end{array}$ & No & Yes/Yes & May vary & $\begin{array}{l}\text { Inconsistent response with } \mathrm{HE} \\
\text { testing/prognostication }\end{array}$ \\
\hline $\begin{array}{l}\text { P300 cognitive } \\
\text { evoked } \\
\text { potentials }\end{array}$ & $\begin{array}{l}\text { An infrequent stimulus } \\
\text { embedded in irrelevant } \\
\text { stimuli is studied }\end{array}$ & No & Yes/Yes & Different ranges & \\
\hline$C F F$ & $\begin{array}{l}\text { Visual discrimination and } \\
\text { general arousal }\end{array}$ & No & Yes/Yes & 10 & Need highly functional patients \\
\hline
\end{tabular}

${ }^{*}$ modified from: Kappus MR, Bajaj JS. Covert hepatic encephalopathy: not as minimal as you might think. Clin Gastroenterol Hepatol 2012;10:1208-1219

NCT-A, number connection test-A; NCT-B, number connection test-B; BDT, block design test; SDT, serial dotting test; DST, digit symbol test; LTT, line tracing test; PHES, psychometric hepatic encephalopathy score; ICT, inhibitory control test; CFF, critical flicker frequency; EEG, electroencephalogram 
previous OHE, a higher prevalence of MHE has already been demonstrated [41]. These findings have attracted increasing interest from the scientific community to verify whether the specific treatment of one or more of these conditions could lead to a consequent improvement in HRQoL.

HRQoL scores were impaired in almost all "Sickness Impact Profile" scales in patients with MHE compared to patients without. Significant impairment is seen in social interaction, alertness, emotional behavior, sleep, work, home management, and recreation and pastimes.

In a study using SF-3, Marchesini et al [46] showed that the etiology and duration of cirrhosis had no effect on HRQoL, whereas minor symptoms, such as pruritus and muscle cramps, had a significant negative impact. In decompensated cirrhosis, MHE impairs the domains of activity, emotional function and global scoring on the chronic lever disease questionnaire. MHE also reduces appetite in cirrhosis and as the liver dysfunction worsens malnutrition occurs, which adversely impacts HRQoL [47].

Prasad et al [10] showed that treating MHE patients with lactulose significantly improved not only their psychometric performance, but also their HRQoL. Such observations have since been confirmed in 115 patients with MHE. In 75\% of patients with MHE resolution, a significant improvement in the "Sickness Impact Profile" and a correlation between improvement in psychometric performance and QoL were observed [45]. Sanyal et al demonstrated that the chronic administration of rifaximin in patients without OHE at enrollment, but with a history of recurring HE, significantly improved HRQoL [48].

\section{MHE and falls}

Patients with liver cirrhosis are at risk of fractures due to osteoporosis secondary to malnutrition, hypogonadism and liver failure [49-51]. The injuries, especially fractures and subsequent surgical sequelae, as well as related hospitalizations, are an important cause of morbidity and mortality in heart failure patients with cirrhosis [52]. The falls and subsequent fractures also have a serious impact on the patient's family and community, and have a high economic impact on the whole of society [53,54]. Roman et al [55] have shown that, because of falls, the need for healthcare $(8.8 \%$ vs. $0 \%, \mathrm{P}=0.004)$ and hospitalization (6.6 vs. $2.3 \%, \mathrm{P}=\mathrm{NS}$ ) was greater in patients with MHE than in cirrhotic patients without MHE. The authors also demonstrated that the intake of psychoactive drugs was related to the presence of MHE and falls (75\% vs. $15 \%$ ). Multivariate analysis identified MHE (odds ratio [OR] 2.91, $95 \%$ confidence interval $[\mathrm{CI}] 1.13-7.48, \mathrm{P}=0.02)$, in addition to a previous history of OHE (OR 2.87, 95\%CI 1.10-7.50, $\mathrm{P}=0.03$ ) and taking psychoactive drugs (OR 3.91, 95\%CI 0.9615.9, $\mathrm{P}=0.05)$, as independent factors associated with falls. These findings were subsequently confirmed by Soriano et al in a larger patient cohort [56]. The authors were able to conclude, using multivariate analysis, that the presence of cognitive impairment, or the presence of MHE diagnosed by an abnormal Psychometric Hepatic Encephalopathy Score (PHES) were the only independent factors predictive of a fall (OR 10.2 95\%CI 3.4-30.4, $\mathrm{P}<0.001$ ). Moreover, the probability of a fall in one year was found to be significantly higher in patients with $\mathrm{MHE}(52 \%$ vs. $6.5 \%, \mathrm{P}<0.0001)$ compared to those without MHE. Urios et al demonstrated that MHE patients show impaired balance, mainly on an unstable surface with eyes open, with longer reaction and confinement times and lower success in stability test limits compared to patients without MHE. In addition, the performance in attention and motor coordination tests correlated with most post-urography parameter alterations. Logistic regression analysis shows that post-urography parameters and the bimanual coordination test seem to be good predictors of falls [57].

\section{Multidimensional impact of cirrhosis and HE on patients, family members, and caregivers}

Liver cirrhosis is a major cause of morbidity and mortality in the United States $[58,59]$. However, in addition to the burden of cirrhosis on the national health system, the impact of cirrhosis and complications such as HE on the family group (represented by both the patient and caregivers, taking account of health, economic and emotional status) is currently being assessed. In fact, eligibility for liver transplantation depends on the family's ability to take on the daily challenges presented by this medical condition, especially in view of the increasing financial impact associated with cirrhosis. Bajaj et al [11] have shown that cirrhosis has a severe impact on the family group in terms of employment (only $56 \%$ of members are in employment) and finances. Patients with previous HE had worse unemployment ( 87.5 vs. $19 \%, \mathrm{P}=0.0001)$ and financial status ( 85 vs. $61 \%, \mathrm{P}=0.019$ ) compared with others.

Agrawal et al confirmed that, because of slowing of psychomotor function and reduced work performance, almost half of MHE patients do not have regular employment, compared to only $15 \%$ of patients without MHE. About $60 \%$ of blue-collar workers are unfit to work, compared to only $20 \%$ of white collar workers, as manual labor is affected more by MHE, whereas verbal intelligence remains preserved. Patients with MHE involved in complex occupational tasks are especially affected, as they endanger themselves as well as others. The impact of MHE on daily life is severe. Diminished work performance and lost wages also involve substantial costs. The socioeconomic implications of the profound negative effects of MHE on functioning in the workplace are significant [60].

Finally, in the liver transplantation setting, Aberg suggests that the prevention of pre-transplant disability by effective treatment of (minimal) HE, maintaining mobility, and planning work adjustments early during chronic liver disease, as well as timely post-transplant physical rehabilitation, continuous encouragement, self-efficacy improvements, and depression management, are key elements in successful employmentpromoting strategies [61]. 


\section{MHE and driving skills}

Driving is a complex and potentially dangerous function, since it involves the integration of visuomotor coordination and selective attention. Visuomotor coordination is governed by all the information and stimuli produced by traffic, road signs and traffic lights, while orientation is an executive function that involves planning, making decisions, calculation of the potential errors, and the inhibitory response. In the US in 2009 there were about 34,000 fatal car crashes with an economic impact of millions of dollars. Thus, it is easy to understand how patients with cirrhosis, especially in cases of cognitive impairment, could be considered as being at extreme risk of road accidents.

Many papers have been published that analyze the relationship between MHE and driving capacity [62-64]. Bajaj et al have shown that patients with MHE diagnosed by ICTs have a $22 \%$ increase in the probability of committing violations of the highway code, compared with $7 \%$ of subjects without MHE [65]. Kircheis et al [66] showed that 52\% of patients with $\mathrm{HE}$ did not possess the minimum eligibility requirements to drive. In the US there are approximately 4 million people suffering from liver cirrhosis and, depending on the case studies, the incidence of MHE amounts to about $60 \%$. Patients with liver cirrhosis and $\mathrm{HE}$ also have a generally optimistic view of their driving skills [67].

Kircheis et al showed that all patients with mild to moderate OHE and $96 \%$ of patients with MHE believed that they were excellent drivers, compared to $92 \%$ of control subjects [66]. However, the driving abilities of individuals with MHE are limited, particularly if analyzed according to criteria based on: 1) a neuropsychological assessment of the cognitive domains involved in the ability to drive [68]; 2) on virtual simulators; or 3) on real driving road tests [64,66]. Bajaj et al [69] also showed how treatment with rifaximin, a slightly absorbable gut antibiotic proposed for the prophylaxis of recurrent OHE [70], also improved psychometric performance ( $91 \%$ vs. $61 \%$ placebo, $\mathrm{P}=0.01$ ). They revealed how, in their 8 -week study, the treatment significantly reduced the errors in simulated driving ( $31 \%$ vs. $76 \%, \mathrm{P}=0.013)$, speeding (33\% vs. $81 \%, \mathrm{P}=0.005)$, and illegal activities ( $19 \%$ vs. $62 \%$, $\mathrm{P}=0.01)$.

\section{MHE and prognosis (survival and development OHE)}

Although MHE represents an early stage in the spectrum of cognitive disorders associated with liver cirrhosis, its presence may correlate with an increase in mortality. Amodio et al [32] were among the first to examine the role of psychometric tests in the prognosis of patients with liver cirrhosis. The results of their "Choice 2" test were, in fact, associated with survival times. Although the model for end-stage liver disease and Child-Pugh scores are currently used in the prognosis, cognitive function also has a significant prognostic value, and thus may be used in combination with these staging systems of the patient's level of severity in terms of liver disease. Dhiman et al [71] studied the correlation of age, level of serum bilirubin, Child-Pugh score, and PHES with prognosis. Patients with MHE showed a higher mortality rate than those without (39.1\% vs. $22.9 \%$ ). Moreover, the multivariate analysis identified two variables as significant independent prognostic factors; psychometric hepatic encephalopathy score $<$ or $=-6$ [hazard ratio 2.419 (95\%CI, 1.014-5.769)] and Child-Turcotte-Pugh score $>$ or $=8$ [hazard ratio 2.466 (95\%CI, 1.010-6.023)] predicted poor survival. In another series, patients suffering from MHE were found to be at risk of developing OHE [59].

\section{Diagnosis of MHE}

There is no single optimal measure for assessing the presence of MHE. In fact, none of the methods proposed cover all aspects of HE: appropriate norms are needed for good sensitivity and specificity in identifying patients at risk of OHE; the rate of pathological results in patient groups without OHE differs markedly; and finally, the results of the various methods are not consistent. However, despite its significant negative impact on the daily lives of patients and caregivers, MHE is still likely to be ignored by most clinicians if standards of neuropsychological testing are not followed while testing a patient for MHE.

\section{PHES test}

This is a battery of tests consisting in five paper-pencil tests that evaluate cognitive and psychomotor processing speed and visuomotor coordination. The tests are relatively easy to administer and have good external validity [21]. PHES is the sum of the scores from all subtests of the battery, normalized for age and level of education. A simplified form of PHES, developed using only three of the original five tests, can be as good as the PHES in diagnosing MHE and in predicting the occurrence of OHE [72]. Table 2 summarizes the most used diagnostic tests.

\section{CFF test}

CFF test is a psychophysiological tool that studies the frequency at which a fused light (presented from $60 \mathrm{~Hz}$ downward) appears to be flickering to the observer. Previous studies have shown a reduction in its performance with worsening cognition and improvement after therapy. The CFF test requires several trials, intact binocular vision, absence of red-green blindness, and specialized equipment $[17,73]$.

\section{Continuous reaction time (CRT) test}

CRT test evaluates the motor reaction time by having the patient press a button in response to auditory stimuli (through headphones). The results give the CRT index, which measures the stability of the reaction times. The test result can 
differentiate between organic and metabolic brain impairment and is not influenced by the patient's age or gender; there is no learning or tiring effect. Simple software and hardware are required [74].

\section{ICT}

ICT is a computerized test that studies the response to inhibitory stimuli and working memory $[33,75]$. The ICT test has been judged to have good validity, but requires highly functional patients.

\section{Stroop test}

Stroop test, also available as an app for a smart phone or tablet, is used to evaluate psychomotor speed and cognitive flexibility by identifying the interference between recognition reaction time to a colored field and a written color name [76].

\section{SCAN test}

SCAN test is a computerized test that measures speed and accuracy in performing a digit recognition memory task of increasing complexity; the test has also been shown to be of prognostic value $[32,77]$.

\section{Animal-naming test}

The animal-naming test, which counts the maximum number of animals listed in $1 \mathrm{~min}$, is also an efficient tool for illiterate patients; it provides an easily obtainable useful measure for the assessment of CHE/MHE [78].

\section{EEG}

EEG is used to detect changes in cortical cerebral activity across the wide spectrum of $\mathrm{HE}$ without patient cooperation or risk of a learning effect. The reliability of EEG analysis can increase with quantitative analysis (including the background frequency with mean dominant frequency or spectral band analysis) [79]. However, it is nonspecific and may be influenced by accompanying metabolic disturbances, such as hyponatremia as well as drugs. In most situations, the EEG requires an institutional setup and neurological expertise in evaluation, and the cost varies among hospitals.

\section{Imaging}

Abnormalities in brain white matter (WM), such as lowgrade edema and structural impairments, have been well- revealed in MHE by magnetic resonance imaging. These WM abnormalities are believed to be responsible for poor neurological performance and brain dysfunctions in MHE and to be associated with $\mathrm{HE}$ development. This thus suggests that WM imaging may be useful in characterizing potential MHE biomarkers. Chen et al used a Bayesian machine-learning technique, called a Graphical-Model-based Multivariate Analysis, to determine WM regions that characterize group differences. They concluded that WM DTI provides useful biomarkers capable of differentiating between MHE and no HE, which would be helpful for the detection of MHE [80]. In a paper by Hassan, MHE that preceded the development of neuropsychological changes was identified by brain (hydrogen-1) magnetic resonance spectroscopy ( $\left.{ }^{1} \mathrm{H}-\mathrm{MRS}\right)$. The authors suggest that ${ }^{1} \mathrm{H}$-MRS may therefore be considered as a potential tool for the diagnosis of cirrhosis-associated cerebral dysfunction and a promising method for prioritization of subjects awaiting liver transplantation [81].

However, there is unfortunately still no optimal diagnostic protocol for the diagnosis of MHE. The "ideal" diagnostic tool should be based on a comparison between the different methods, on the evidence of the association of each of them with significant clinical outcomes-such as the ability to perform tasks that are potentially dangerous in real life, such as driving - and on patients' QoL, development of episodes of OHE and survival.

The diagnostic tools mentioned above are also used to test for MHE and CHE; however, they do not correlate well with each other because $\mathrm{HE}$ is a multidimensional dysfunction [82]. Moreover, there is often a learning effect with psychometric tests and it is unclear whether current HE therapy plays a role in the test performance. Therefore, the interpretation of these tests and the use of the results for further management require a complete evaluation of the patient's history, the current therapy, as well as the effect on the patient's daily activities. Due to the high incidence of MHE and CHE in patients with liver cirrhosis, each patient considered at risk should "ideally" be tested. However, this strategy may be costly [63]. In addition, the consequences of this screening strategy are still not always clear and a specific treatment-i.e., rifaximin, non-absorbable disaccharides, probiotics-is not always recommended unless on a case-by-case basis.

A cost-effective diagnostic approach may be to test patients who have an impairment in their QoL or fitness to drive [83]. It is also important to test only those patients who do not have confounding factors, such as neuropsychiatric disorders, those on psychoactive medication, or those who report current alcohol use or pharmacological treatment for HE; moreover, testing should be done only by a trained examiner [84]. If the test result is normal (i.e., negative for MHE or CHE), guidelines suggest repeating the test after six months [85]. For multicenter studies, AASLD/EASL guidelines for the management of $\mathrm{HE}$ [86] suggest that the diagnosis of MHE or CHE by consensus should use at least two of the current validated testing strategies: paper-pencil (PHES) and one of the following: computerized (CRT, ICT, SCAN, or Stroop) or neurophysiological (CFF or EEG). 


\section{Treatment}

Despite its subtle nature, MHE and CHE can have a significant effect on a patient's daily life, and in special circumstances (e.g., impairment of driving skills or work performance, poor QoL, or cognitive complaints) the indication to treat the patient may prevail. However, because of the multiple methods used to define MHE and CHE (even based on normative data for a studied population), the varying and multiple endpoints, short-term treatment trials, and differing agents used in trials to date, recently published guidelines state that treatment of MHE and CHE is not routinely recommended apart from on a case-by-case basis [85]. Table 3 provides a complete overview of the studies of MHE treatment.

\section{Rifaximin}

Rifaximin is an oral non-systemic broad-spectrum antibiotic, structurally similar to rifampin. By binding to bacterial DNA-dependent RNA polymerase, rifaximin inhibits bacterial RNA/protein synthesis. Structurally, the benzimidazole ring limits systemic absorption by $0.4 \%$, with the primary mode of excretion via feces and low levels of drug excreted in the urine or bile. Concentrated in the gut, rifaximin is presumed to modulate intestinal bacteria, thereby reducing intestinal ammonia and toxin formation. Bajaj et al demonstrated that patients with MHE treated with rifaximin for an 8-week period showed significantly greater improvements in driving and cognitive performance and in the psychosocial dimension of the Sickness Impact Profile than those given a placebo [69]. These results were confirmed in another randomized controlled trial (RCT), in which the authors demonstrated that rifaximin significantly improves both cognitive functions and HRQoL in patients with MHE [45]. Recently, an RCT comparing rifaximin with lactulose for MHE reversal and HrQoL amelioration failed to demonstrate significant differences between groups [86].

\section{Non-absorbable disaccharides}

Lactulose or lactitol are synthetic non-absorbable disaccharides extensively used in the management of OHE. Lactulose is fermented in the colon into acetic and lactic acid, resulting in the acidification of intestinal contents and conversion of ammonia $\left(\mathrm{NH}_{3}\right)$ to ammonium $\left(\mathrm{NH}_{4}^{+}\right)$. Unlike ammonia, ammonium is not systemically absorbed and is excreted in stool. Lactulose also has a cathartic effect, increasing nitrogen excretion fourfold.

Although Prasad et al [10] concluded that treatment with lactulose improves both cognitive function and HRQoL in patients with cirrhosis who have MHE, most subsequent studies have not provided strong evidence on the efficacy of non-absorbable disaccharides in MHE treatment [45,87-90]. A meta-analysis evaluating the role of pharmacological treatment with non-absorbable disaccharides in patients with MHE failed to show clear evidence that any treatment played a convincing role in improving cognitive function and HRQoL [91].

\section{Probiotics}

Probiotics are live microorganisms that alter the balance of intestinal microflora, and synbiotics are probiotics with the addition of fermentable fiber. It is presumed that reducing intestinal bacterial urease activity decreases the absorption of ammonia and other gut-derived toxins that result in oxidative stress/inflammation.

Seven recently published RCTs have tried to evaluate the role of probiotic treatment/supplementation in treating MHE. Unfortunately, the results do not support the evidence on the efficacy in MHE reversal of a treatment with probiotics alone or in addition to other drugs [88-90,92-95]. In fact, no significant difference in the improvement of MHE, hospitalization rates, or progression to OHE has been reported when probiotics were compared with lactulose [96].

\section{Branched-chain amino acids}

A meta-analysis that evaluated the role of pharmacological treatment with branched-chain amino acids in patients with MHE reported no significant difference in the improvement of MHE [97].

\section{LOLA (L-ornithine-L-aspartate)}

LOLA has been shown to reduce ammonia levels $[98,99]$ by upregulating glutamine synthetase and urea cycle activity [100]. L-ornithine and L-aspartate are separately metabolized to form glutamate, which, combined with ammonia, results in the formation of glutamine. Therefore, LOLA lowers plasma ammonia concentrations by enhancing the metabolism of ammonia to glutamine. Bai et al evaluated eight RCTs (646 total patients, $46 \%$ diagnosed with MHE), assessing the efficacy of LOLA compared to placebo in patients with cirrhosis. Treatment with LOLA diminished serum ammonia levels with no increase in adverse reactions [100].

\section{Grey areas and future needs}

MHE and CHE correspond to a broad spectrum of neuropsychological manifestations of liver disease that require quantification and in which differential diagnoses should be carefully considered. The detection of risk thresholds for the occurrence of OHE, impairment in daily life activities and in QoL has unfortunately not yet been well defined. Therefore, future clinical research should try to detect such thresholds. 


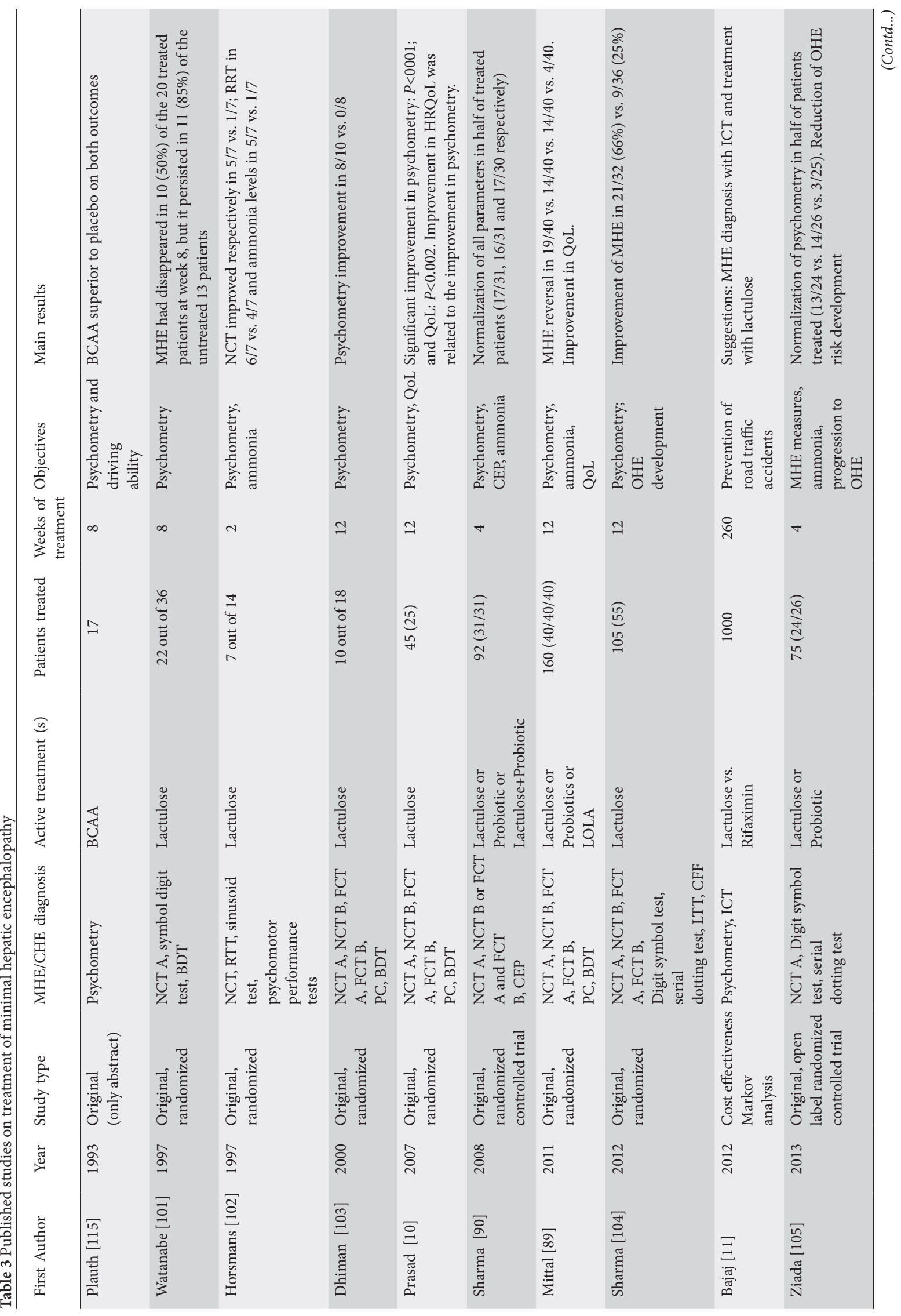




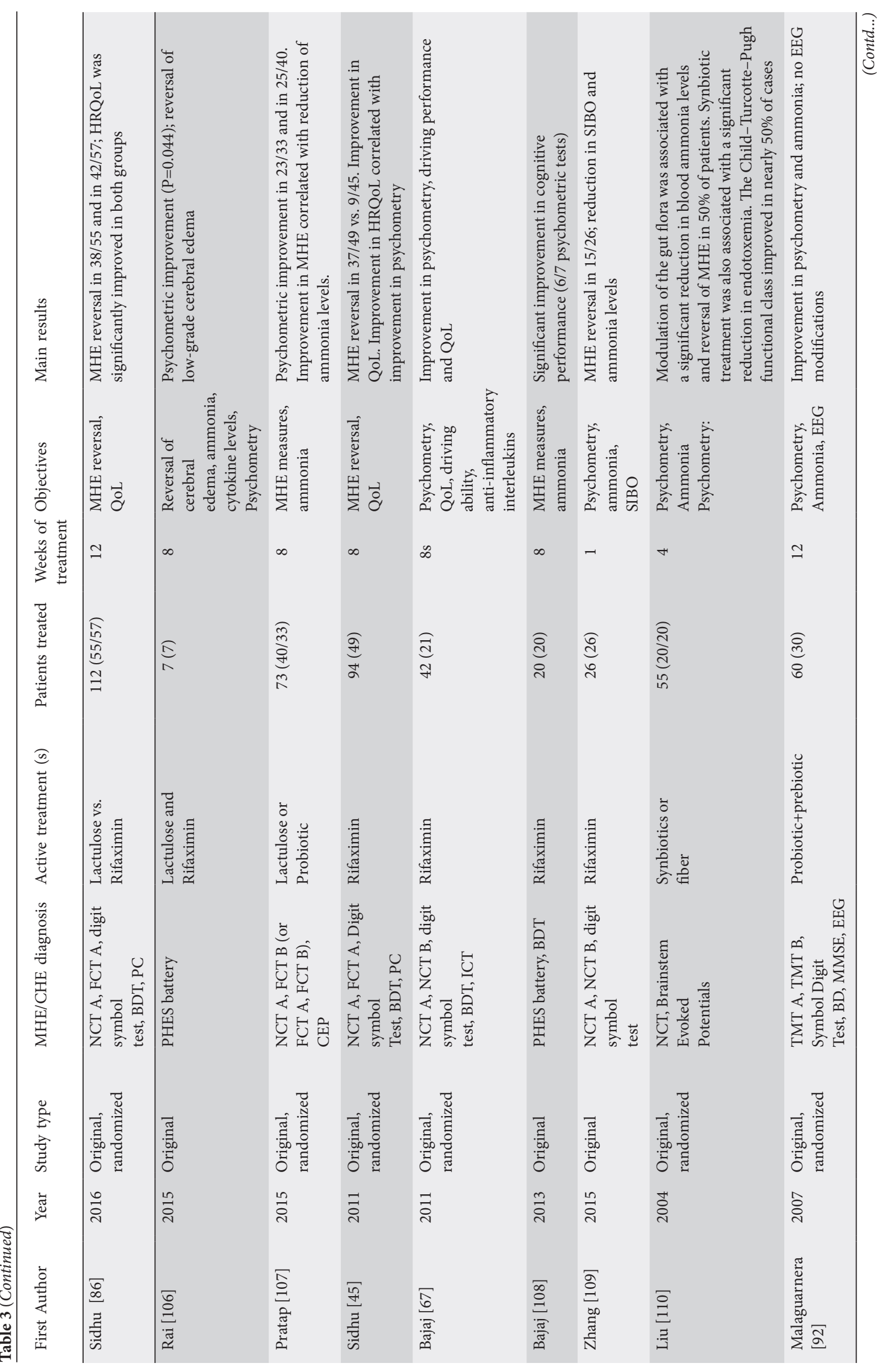




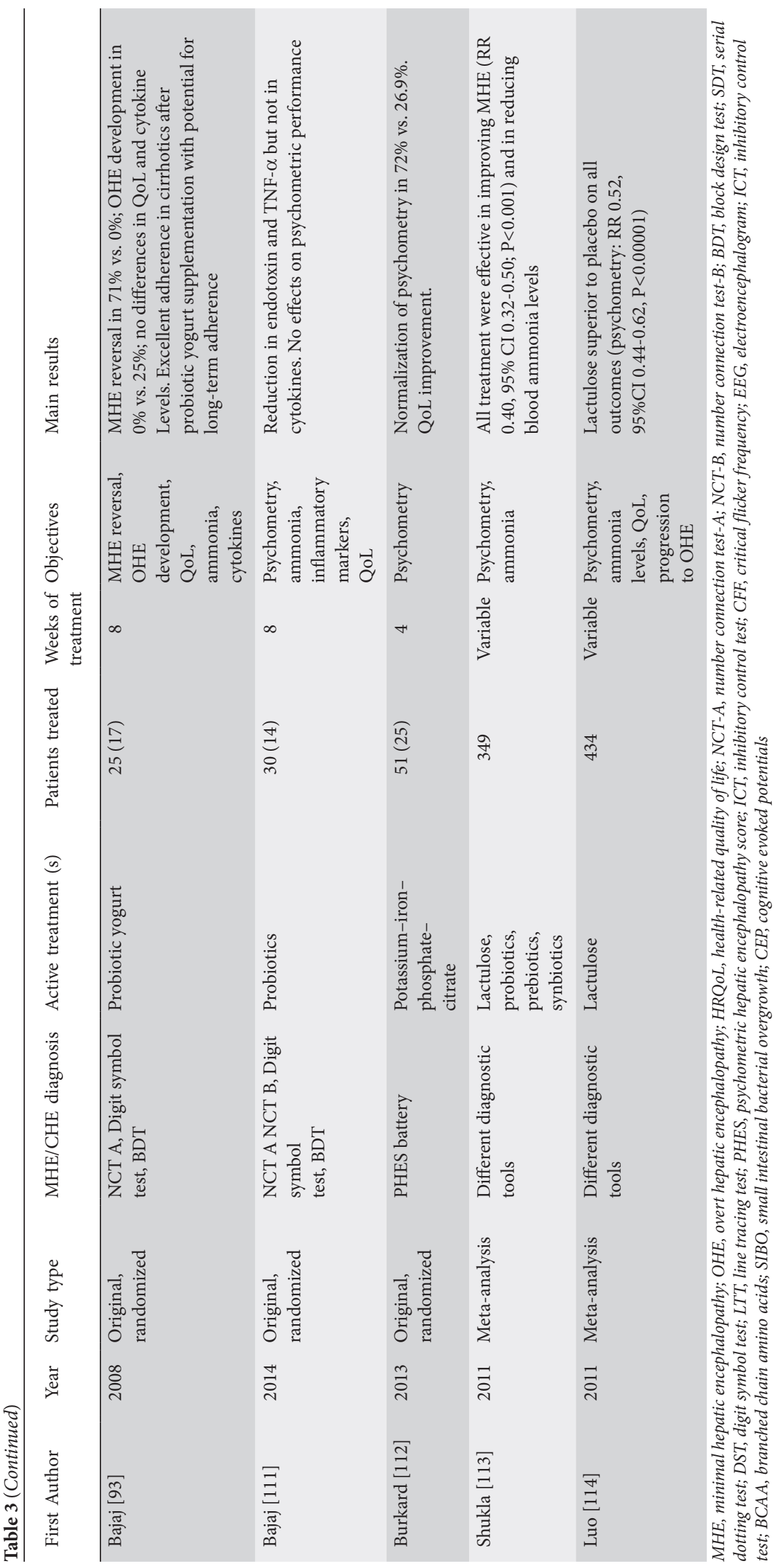


The diagnostic methods needed to form the basis for clinical trials also need to be investigated. The diagnosis of MHE and $\mathrm{CHE}$ has received considerable interest; however, it is still not possible to compare results among studies and the precision needs improving.

One important area of uncertainty is whether the term $\mathrm{CHE}$, introduced to expand MHE to grade I oriented patients, is actually informative and clinically valuable. A closer scientific collaboration between clinical hepatologists and brain researchers, including functional brain imaging experts, is needed, and neuropsychologists and psychiatrists may also be needed to clarify the broad spectrum of neuropsychiatric symptoms observed in patients with liver disease.

The proposed treatment for MHE and CHE is actually the same as the one used for the treatment/prophylaxis of OHE; however, in most cases these strategies only manage to ameliorate the indices of brain function (psychometric or neurophysiological) or lower ammonia. In addition, other treatment strategies are reasonably based on an alternative approach that considers drug use after having tested the efficacy of dietetic counseling, modification of gut microflora, as well as the correction of confounders or precipitating factors for HE, such as hyponatremia, or possibly based on a more complete knowledge of changes in human gut microbiota and the neurobiology of the encephalopathy.

Studies specifically aimed at establishing whether the treatment of MHE is able to affect clinically relevant endpoints are therefore greatly needed. The patients' inclusion should be based on the objective definition of the presence of minimal or CHE. The modification of psychometric tests should not be chosen as the main endpoint of the study; the tests should instead be used merely as a criterion to include comparable patients. The sample size should be calculated according to one of the clinically relevant endpoints, such as the QoL or the incidence of OHE; data on these outcomes are available in the literature. The assessment of the efficacy of a given treatment to prevent $\mathrm{OHE}$ in patients with MHE requires the organization of large multicenter studies. A parallel design with a placebo or a no-treatment arm is mandatory. Because MHE is a chronic condition, the choice of the drug to be tested should be limited to those that can be administered for a very long period of time without significant side-effects. Among the emerging drugs, modulators of the intestinal bacterial flora should be the first candidates to be tested in this field. Future studies should fill the gaps in our knowledge.

\section{References}

1. Ferenci P, Lockwood A, Mullen K, Tarter R, Weissenborn K, Blei AT. Hepatic encephalopathy-definition, nomenclature, diagnosis, and quantification: final report of the working party at the $11^{\text {th }}$ World Congresses of Gastroenterology, Vienna, 1998. Hepatology 2002;35:716-721.

2. Gitlin N, Lewis DC, Hinkley L. The diagnosis and prevalence of subclinical hepatic encephalopathy in apparently healthy, ambulant, non-shunted patients with cirrhosis. J Hepatol 1986;3:75-82.
3. Lockwood AH. "What's in a name?" Improving the care of cirrhotics. J Hepatol 2000;32:859-861.

4. Amodio P, Montagnese S, Gatta A, Morgan MY. Characteristics of minimal hepatic encephalopathy. Metab Brain Dis 2004; 19:253-267.

5. McCrea M, Cordoba J, Vessey G, Blei AT, Randolph C. Neuropsychological characterization and detection of subclinical hepatic encephalopathy. Arch Neurol 1996;53:758-763.

6. Rakoski MO, McCammon RJ, Piette JD, et al. Burden of cirrhosis on older Americans and their families: analysis of the health and retirement study. Hepatology 2012;55:184-191.

7. Kappus MR, Bajaj JS. Covert hepatic encephalopathy: not as minimal as you might think. Clin Gastroenterol Hepatol 2012;10:1208-1219.

8. Bajaj JS, Riggio O, Allampati S, et al. Cognitive dysfunction is associated with poor socioeconomic status in patients with cirrhosis: an international multicenter study. Clin Gastroenterol Hepatol 2013;11:1511-1516.

9. Bajaj JS, Hafeezullah M, Hoffmann RG, et al. Navigation skill impairment: another dimension of the driving difficulties in minimal hepatic encephalopathy. Hepatology 2008;47:596-604.

10. Prasad S, Dhiman RK, Duseja A, Chawla YK, Sharma A, Agarwal R. Lactulose improves cognitive functions and healthrelated quality of life in patients with cirrhosis who have minimal hepatic encephalopathy. Hepatology 2007;45:549-559.

11. Bajaj JS, Wade JB, Gibson DP, et al. The multi-dimensional burden of cirrhosis and hepatic encephalopathy on patients and caregivers. Am J Gastroenterol 2011;106:1646-1653.

12. Groeneweg M, Moerland W, Quero JC, Hop WC, Krabbe PF, Schalm SW. Screening of subclinical hepatic encephalopathy. J Hepatol 2000;32:748-753.

13. Saxena N, Bhatia M, Joshi YK, Garg PK, Tandon RK. Auditory P300 event-related potentials and number connection test for evaluation of subclinical hepatic encephalopathy in patients with cirrhosis of the liver: a follow-up study. J Gastroenterol Hepatol 2001; 16:322-327.

14. Schomerus H, Hamster W. Quality of life in cirrhotics with minimal hepatic encephalopathy. Metab Brain Dis 2001;16:37-41.

15. Sharma P, Sharma BC, Puri V, Sarin SK. Critical flicker frequency: diagnostic tool for minimal hepatic encephalopathy. $J$ Hepatol 2007;47:67-73.

16. Bajaj JS. Management options for minimal hepatic encephalopathy. Expert Rev Gastroenterol Hepatol 2008;2:785-790.

17. Romero-Gómez M, Córdoba J, Jover R, et al. Value of the critical flicker frequency in patients with minimal hepatic encephalopathy. Hepatology 2007;45:879-885.

18. Bajaj JS, Saeian K, Verber MD, et al. Inhibitory control test is a simple method to diagnose minimal hepatic encephalopathy and predict development of overt hepatic encephalopathy. Am J Gastroenterol 2007;102:754-760.

19. Ford JM, Gray M, Whitfield SL, et al. Acquiring and inhibiting prepotent responses in schizophrenia: event-related brain potentials and functional magnetic resonance imaging. Arch Gen Psychiatry 2004;61:119-129.

20. Schiff S, Vallesi A, Mapelli D, et al. Impairment of response inhibition precedes motor alteration in the early stage of liver cirrhosis: a behavioral and electrophysiological study. Metab Brain Dis 2005;20:381-392.

21. Weissenborn K, Ennen JC, Schomerus H, Rückert N, Hecker H. Neuropsychological characterization of hepatic encephalopathy. J Hepatol 2001;34:768-773.

22. Córdoba J, Cabrera J, Lataif L, Penev P, Zee P, Blei AT. High prevalence of sleep disturbance in cirrhosis. Hepatology 1998;27:339-345.

23. Franco RA, Ashwathnarayan R, Deshpandee A, et al. The high prevalence of restless legs syndrome symptoms in liver disease 
in an academic-based hepatology practice. J Clin Sleep Med 2008;4:45-49.

24. Martino ME, Romero-Vives M, Fernández-Lorente J, De Vicente E, Bárcena R, Gaztelu JM. Sleep electroencephalogram alterations disclose initial stage of encephalopathy. Methods Find Exp Clin Pharmacol 2002;24 Suppl D:119-122.

25. Mostacci B, Ferlisi M, Baldi Antognini A, et al. Sleep disturbance and daytime sleepiness in patients with cirrhosis: a case control study. Neurol Sci 2008;29:237-240.

26. Bajaj JS, Cordoba J, Mullen KD, et al; International Society for Hepatic Encephalopathy and Nitrogen Metabolism (ISHEN). Review article: the design of clinical trials in hepatic encephalopathy-an International Society for Hepatic Encephalopathy and Nitrogen Metabolism (ISHEN) consensus statement. Aliment Pharmacol Ther 2011;33:739-747.

27. Bustamante J, Rimola A, Ventura PJ, et al. Prognostic significance of hepatic encephalopathy in patients with cirrhosis. J Hepatol 1999;30:890-895.

28. Hartmann IJ, Groeneweg M, Quero JC, et al. The prognostic significance of subclinical hepatic encephalopathy. Am J Gastroenterol 2000;95:2029-2034.

29. Gentilini P, Laffi G, La Villa G, et al. Long course and prognostic factors of virus-induced cirrhosis of the liver. Am J Gastroenterol 1997;92:66-72.

30. Benvegnù L, Gios M, Boccato S, Alberti A. Natural history of compensated viral cirrhosis: a prospective study on the incidence and hierarchy of major complications. Gut 2004;53:744-749.

31. Watson H, Jepsen P, Wong F, Ginès P, Córdoba J, Vilstrup H. Satavaptan treatment for ascites in patients with cirrhosis: a metaanalysis of effect on hepatic encephalopathy development. Metab Brain Dis 2013;28:301-305.

32. Amodio P, Del Piccolo F, Marchetti P, et al. Clinical features and survival of cirrhotic patients with subclinical cognitive alterations detected by the number connection test and computerized psychometric tests. Hepatology 1999;29:1662-1667.

33. Bajaj JS, Hafeezullah M, Franco J, et al. Inhibitory control test for the diagnosis of minimal hepatic encephalopathy. Gastroenterology 2008;135:1591-1600.

34. Weissenborn K, Scholz M, Hinrichs H, Wiltfang J, Schmidt FW, Künkel H. Neurophysiological assessment of early hepatic encephalopathy. Electroencephalogr Clin Neurophysiol 1990;75:289-295.

35. Bajaj JS, Etemadian A, Hafeezullah M, Saeian K. Testing for minimal hepatic encephalopathy in the United States: An AASLD survey. Hepatology 2007;45:833-834.

36. Groeneweg M, Quero JC, De Bruijn I, et al. Subclinical hepatic encephalopathy impairs daily functioning. Hepatology 1998;28:45-49.

37. Arguedas MR, DeLawrence TG, McGuire BM. Influence of hepatic encephalopathy on health-related quality of life in patients with cirrhosis. Dig Dis Sci 2003;48:1622-1626.

38. Saab S, Ibrahim AB, Shpaner A, et al. MELD fails to measure quality of life in liver transplant candidates. Liver Transpl 2005;11:218-223.

39. Younossi ZM, Boparai N, Price LL, Kiwi ML, McCormick M, Guyatt G. Health-related quality of life in chronic liver disease: the impact of type and severity of disease. Am J Gastroenterol 2001;96:2199-2205.

40. Younossi ZM, McCormick M, Price LL, et al. Impact of liver transplantation on health-related quality of life. Liver Transpl 2000;6:779-783.

41. Bajaj JS, Schubert CM, Heuman DM, et al. Persistence of cognitive impairment after resolution of overt hepatic encephalopathy. Gastroenterology 2010;138:2332-2340.

42. Riggio O, Ridola L, Pasquale C, et al. Evidence of persistent cognitive impairment after resolution of overt hepatic encephalopathy. Clin Gastroenterol Hepatol 2011;9:181-183.
43. McNeil BJ, Weichselbaum R, Pauker SG. Speech and survival: tradeoffs between quality and quantity of life in laryngeal cancer. N Engl J Med 1981;305:982-987.

44. Bao ZJ, Qiu DK, Ma X, et al. Assessment of health-related quality of life in Chinese patients with minimal hepatic encephalopathy. World J Gastroenterol 2007;13:3003-3008.

45. Sidhu SS, Goyal O, Mishra BP, Sood A, Chhina RS, Soni RK. Rifaximin improves psychometric performance and health-related quality of life in patients with minimal hepatic encephalopathy (the RIME Trial). Am J Gastroenterol 2011;106:307-316.

46. Marchesini G, Bianchi G, Amodio P, et al; Italian Study Group for quality of life in cirrhosis. Factors associated with poor healthrelated quality of life of patients with cirrhosis. Gastroenterology 2001;120:170-178.

47. Mina A, Moran S, Ortiz-Olvera N, Mera R, Uribe M. Prevalence of minimal hepatic encephalopathy and quality of life in patients with decompensated cirrhosis. Hepatol Res 2014;44:E92-E99.

48. Sanyal A, Younossi ZM, Bass NM, et al. Randomised clinical trial: rifaximin improves health-related quality of life in cirrhotic patients with hepatic encephalopathy - a double-blind placebocontrolled study. Aliment Pharmacol Ther 2011;34:853-861.

49. Collier J. Bone disorders in chronic liver disease. Hepatology 2007;46:1271-1278.

50. Guañabens N, Parés A, Ros I, et al. Severity of cholestasis and advanced histological stage but not menopausal status are the major risk factors for osteoporosis in primary biliary cirrhosis. J Hepatol 2005;42:573-577.

51. Diamond T, Stiel D, Lunzer M, Wilkinson M, Roche J, Posen S. Osteoporosis and skeletal fractures in chronic liver disease. Gut 1990;31:82-87.

52. Cohen SM, Te HS, Levitsky J. Operative risk of total hip and knee arthroplasty in cirrhotic patients. J Arthroplasty 2005;20:460-466.

53. Ström O, Borgstrom F, Zethraeus N, et al. Long-term cost and effect on quality of life of osteoporosis-related fractures in Sweden. Acta Orthop 2008;79:269-280.

54. Pike C, Birnbaum HG, Schiller M, Sharma H, Burge R, Edgell ET. Direct and indirect costs of non-vertebral fracture patients with osteoporosis in the US. Pharmacoeconomics 2010;28:395-409.

55. Román E, Córdoba J, Torrens $\mathrm{M}$, et al. Minimal hepatic encephalopathy is associated with falls. Am J Gastroenterol 2011;106:476-482.

56. Soriano G, Román E, Córdoba J, et al. Cognitive dysfunction in cirrhosis is associated with falls: a prospective study. Hepatology 2012;55:1922-1930.

57. Urios A, Mangas-Losada A, Gimenez-Garzó C, et al. Altered postural control and stability in cirrhotic patients with minimal hepatic encephalopathy correlate with cognitive deficits. Liver Int 2017;37:1013-1022.

58. Kim WR, Brown RS Jr, Terrault NA, El-Serag H. Burden of liver disease in the United States: summary of a workshop. Hepatology 2002;36:227-242.

59. Poordad FF. Review article: the burden of hepatic encephalopathy. Aliment Pharmacol Ther 2007;25 Suppl 1:3-9.

60. Agrawal S, Umapathy S, Dhiman RK. Minimal hepatic encephalopathy impairs quality of life. J Clin Exp Hepatol 2015;5:S42-S48.

61. Aberg F. From prolonging life to prolonging working life: tackling unemployment among liver-transplant recipients. World $J$ Gastroenterol 2016;22:3701-3711.

62. Bajaj JS, Pinkerton SD, Sanyal AJ, Heuman DM. Diagnosis and treatment of minimal hepatic encephalopathy to prevent motor vehicle accidents: a cost-effectiveness analysis. Hepatology 2012;55:1164-1171.

63. Bajaj JS, Hafeezullah M, Hoffmann RG, Saeian K. Minimal hepatic encephalopathy: a vehicle for accidents and traffic violations. Am J Gastroenterol 2007;102:1903-1909. 
64. Wein C, Koch H, Popp B, Oehler G, Schauder P. Minimal hepatic encephalopathy impairs fitness to drive. Hepatology 2004;39:739-745.

65. Bajaj JS, Saeian K, Schubert CM, et al. Minimal hepatic encephalopathy is associated with motor vehicle crashes: the reality beyond the driving test. Hepatology 2009;50:1175-1183.

66. Kircheis G, Knoche A, Hilger N, et al. Hepatic encephalopathy and fitness to drive. Gastroenterology 2009;137:1706-1715.e1-e9.

67. Bajaj JS, Saeian K, Hafeezullah M, Hoffmann RG, Hammeke TA. Patients with minimal hepatic encephalopathy have poor insight into their driving skills. Clin Gastroenterol Hepatol 2008;6:1135-1139.

68. Schomerus H, Hamster W, Blunck H, Reinhard U, Mayer K, Dölle W. Latent portasystemic encephalopathy. I. Nature of cerebral functional defects and their effect on fitness to drive. Dig Dis Sci 1981;26:622-630.

69. Bajaj JS, Heuman DM, Wade JB, et al. Rifaximin improves driving simulator performance in a randomized trial of patients with minimal hepatic encephalopathy. Gastroenterology 2011;140:478-487.

70. Bass NM, Mullen KD, Sanyal A, et al. Rifaximin treatment in hepatic encephalopathy. N Engl J Med 2010;362:1071-1081.

71. Dhiman RK, Kurmi R, Thumburu KK, et al. Diagnosis and prognostic significance of minimal hepatic encephalopathy in patients with cirrhosis of liver. Dig Dis Sci 2010;55:2381-2390.

72. Riggio O, Ridola L, Pasquale C, et al. A simplified psychometric evaluation for the diagnosis of minimal hepatic encephalopathy. Clin Gastroenterol Hepatol 2011;9:613-616.e1.

73. Kircheis G, Wettstein M, Timmermann L, Schnitzler A, Häussinger D. Critical flicker frequency for quantification of lowgrade hepatic encephalopathy. Hepatology 2002;35:357-366.

74. Lauridsen MM, Thiele M, Kimer N, Vilstrup H. The continuous reaction times method for diagnosing, grading, and monitoring minimal/covert hepatic encephalopathy. Metab Brain Dis 2013;28:231-234.

75. Amodio P, Ridola L, Schiff S, et al. Improving the inhibitory control task to detect minimal hepatic encephalopathy. Gastroenterology 2010;139:510-518, 518.e1-e2.

76. Bajaj JS, Thacker LR, Heuman DM, et al. The Stroop smartphone application is a short and valid method to screen for minimal hepatic encephalopathy. Hepatology 2013;58:1122-1132.

77. Montagnese S, Schiff S, Turco M, et al. Simple tools for complex syndromes: a three-level difficulty test for hepatic encephalopathy. Dig Liver Dis 2012;44:957-960.

78. Campagna F, Montagnese S, Ridola L, et al. The animal naming test: an easy tool for the assessment of hepatic encephalopathy. Hepatology 2017;66:198-208.

79. Guerit JM, Amantini A, Fischer C, et al; members of the ISHEN commission on Neurophysiological Investigations. Neurophysiological investigations of hepatic encephalopathy: ISHEN practice guidelines. Liver Int 2009;29:789-796.

80. Chen HJ, Chen R, Yang M, Teng GJ, Herskovits EH. Identification of minimal hepatic encephalopathy in patients with cirrhosis based on white matter imaging and Bayesian data mining. AJNR Am J Neuroradiol 2015;36:481-487.

81. Hassan EA, Abd El-Rehim AS, Seifeldein GS, Shehata GA. Minimal hepatic encephalopathy in patients with liver cirrhosis: magnetic resonance spectroscopic brain findings versus neuropsychological changes. Arab J Gastroenterol 2014;15:108-113.

82. Montagnese S, Biancardi A, Schiff S, et al. Different biochemical correlates for different neuropsychiatric abnormalities in patients with cirrhosis. Hepatology 2010;53:558-566.

83. Ortiz M, Jacas C, Córdoba J. Minimal hepatic encephalopathy: diagnosis, clinical significance and recommendations. J Hepatol 2005;42 Suppl: S45-S53.

84. Prakash RK, Brown TA, Mullen KD. Minimal hepatic encephalopathy and driving: is the genie out of the bottle? Am J Gastroenterol 2011;106:1415-1416.

85. Vilstrup H, Amodio P, Bajaj J, et al. Hepatic encephalopathy in chronic liver disease: 2014 Practice Guideline by the American Association for the Study of Liver Diseases and the European Association for the Study of the Liver. Hepatology 2014;60:715-735.

86. Sidhu SS, Goyal O, Parker RA, Kishore H, Sood A. Rifaximin vs. lactulose in treatment of minimal hepatic encephalopathy. Liver Int 2016;36:378-385.

87. Schulz C, Schütte K, Kropf S, et al. RiMINI - the influence of rifaximin on minimal hepatic encephalopathy (MHE) and on the intestinal microbiome in patients with liver cirrhosis: study protocol for a randomized controlled trial. Trials 2016;17:111.

88. Lunia MK, Sharma BC, Sharma P, Sachdeva S, Srivastava S. Probiotics prevent hepatic encephalopathy in patients with cirrhosis: a randomized controlled trial. Clin Gastroenterol Hepatol 2014;12:1003-1008.e1.

89. Mittal VV, Sharma BC, Sharma P, Sarin SK. A randomized controlled trial comparing lactulose, probiotics, and L-ornithine L-aspartate in treatment of minimal hepatic encephalopathy. Eur J Gastroenterol Hepatol 2011;23:725-732.

90. Sharma P, Sharma BC, Puri V, Sarin SK. An open-label randomized controlled trial of lactulose and probiotics in the treatment of minimal hepatic encephalopathy. Eur J Gastroenterol Hepatol 2008;20:506-511.

91. Gluud LL, Vilstrup H, Morgan MY. Non-absorbable disaccharides versus placebo/no intervention and lactulose versus lactitol for the prevention and treatment of hepatic encephalopathy in people with cirrhosis. Cochrane Database Syst Rev 2016;(5):CD003044.

92. Malaguarnera M, Greco F, Barone G, Gargante MP, Malaguarnera M, Toscano MA. Bifidobacterium longum with fructo-oligosaccharide (FOS) treatment in minimal hepatic encephalopathy: a randomized, double-blind, placebo-controlled study. Dig Dis Sci 2007;52:3259-3265.

93. Bajaj JS, Saeian K, Christensen KM, et al. Probiotic yogurt for the treatment of minimal hepatic encephalopathy. Am J Gastroenterol 2008;103:1707-1715.

94. Saji S, Kumar S, Thomas V. A randomized double blind placebo controlled trial of probiotics in minimal hepatic encephalopathy. Trop Gastroenterol 2011;32:128-132.

95. Sharma K, Pant S, Misra S, et al. Effect of rifaximin, probiotics, and l-ornithine l-aspartate on minimal hepatic encephalopathy: a randomized controlled trial. Saudi J Gastroenterol 2014;20:225-232.

96. Dalal R, McGee RG, Riordan SM, Webster AC. Probiotics for people with hepatic encephalopathy. Cochrane Database Syst Rev 2017;2:CD008716.

97. Gluud LL, Dam G, Les I, et al. Branched-chain amino acids for people with hepatic encephalopathy. Cochrane Database Syst Rev 2015;(9):CD001939.

98. Kircheis G, Nilius R, Held C, et al. Therapeutic efficacy of L-ornithine-L-aspartate infusions in patients with cirrhosis and hepatic encephalopathy: results of a placebo-controlled, doubleblind study. Hepatology 1997;25:1351-1360.

99. Poo JL, Góngora J, Sánchez-Avila F, et al. Efficacy of oral L-ornithineL-aspartate in cirrhotic patients with hyperammonemic hepatic encephalopathy. Results of a randomized, lactulose-controlled study. Ann Hepatol 2006;5:281-288.

100. Bai M, Yang Z, Qi X, Fan D, Han G. L-ornithine-L-aspartate for hepatic encephalopathy in patients with cirrhosis: a meta-analysis of randomized controlled trials. J Gastroenterol Hepatol 2013;28:783-792.

101. Watanabe A, Sakai T, Sato S, et al. Clinical efficacy of lactulose in cirrhotic patients with and without subclinical hepatic encephalopathy. Hepatology 1997;26:1410-1414.

102.Horsmans Y, Solbreux PM, Daenens C, Desager JP, Geubel AP. Lactulose improves psychometric testing in cirrhotic patients with subclinical encephalopathy. Aliment Pharmacol Ther 1997;11:165-170. 
103. Dhiman RK, Sawhney MS, Chawla YK, Das G, Ram S, Dilawari JB. Efficacy of lactulose in cirrhotic patients with subclinical hepatic encephalopathy. Dig Dis Sci 2000;45:1549-1552.

104. Sharma P, Sharma BC, Agrawal A, Sarin SK. Primary prophylaxis of overt hepatic encephalopathy in patients with cirrhosis: an open labeled randomized controlled trial of lactulose versus no lactulose. J Gastroenterol Hepatol 2012;27:1329-1335.

105. Ziada DH, Soliman HH, El Yamany SA, Hamisa MF, Hasan AM. Can Lactobacillus acidophilus improve minimal hepatic encephalopathy? A neurometabolite study using magnetic resonance spectroscopy. Arab J Gastroenterol 2013;14:116-122.

106. Rai R, Ahuja CK, Agrawal S, et al. Reversal of low-grade cerebral edema after lactulose/rifaximin therapy in patients with cirrhosis and minimal hepatic encephalopathy. Clin Transl Gastroenterol 2015;6:e111.

107. Pratap Mouli V, Benjamin J, Bhushan Singh M, et al. Effect of probiotic VSL\#3 in the treatment of minimal hepatic encephalopathy: A non-inferiority randomized controlled trial. Hepatol Res 2015;45:880-889.

108. Bajaj JS, Heuman DM, Sanyal AJ, et al. Modulation of the metabiome by rifaximin in patients with cirrhosis and minimal hepatic encephalopathy. PLoS One 2013;8:e60042.

109. Zhang Y, Feng Y, Cao B, Tian Q. Effects of SIBO and rifaximin therapy on MHE caused by hepatic cirrhosis. Int J Clin Exp Med 2015;8:2954-2957.
110. Liu Q, Duan ZP, Ha DK, Bengmark S, Kurtovic J, Riordan SM. Synbiotic modulation of gut flora: effect on minimal hepatic encephalopathy in patients with cirrhosis. Hepatology 2004;39:1441-1449.

111. Bajaj JS, Heuman DM, Hylemon PB, et al. Randomised clinical trial: Lactobacillus GG modulates gut microbiome, metabolome and endotoxemia in patients with cirrhosis. Aliment Pharmacol Ther 2014;39:1113-1125.

112. Burkard T, Biedermann A, Herold C, Dietlein M, Rauch M, Diefenbach M. Treatment with a potassium-iron-phosphatecitrate complex improves PSE scores and quality of life in patients with minimal hepatic encephalopathy: a multicenter, randomized, placebo-controlled, double-blind clinical trial. Eur J Gastroenterol Hepatol 2013;25:352-358.

113. Shukla S, Shukla A, Mehboob S, Guha S. Meta-analysis: the effects of gut flora modulation using prebiotics, probiotics and synbiotics on minimal hepatic encephalopathy. Aliment Pharmacol Ther 2011;33:662-671.

114. Luo M, Li L, Lu CZ, Cao WK. Clinical efficacy and safety of lactulose for minimal hepatic encephalopathy: a meta-analysis. Eur J Gastroenterol Hepatol 2011;23:1250-1257.

115. Plauth M, Egberts EH, Hamster W. Long-term treatment of latent portosystemic encephalopathy with branched-chain amino acids. A double-blind placebo-controlled crossover study. J Hepatol 1993;17:308-314. 